\title{
Aspectos semântico-lexicais dos tabus linguísticos em atlas linguísticos estaduais
}

\author{
Laura de Almeida*
}

\begin{abstract}
This paper aims to study the linguistic taboos in the following linguistic atlases: Atlas Prévio dos Falares Baianos (APFB), Atlas Linguístico de Sergipe I (ALSE I), Atlas Linguístico da Paraíba (Alpa). We selected the topics referring to item IIHomem from the "Questionário Semântico-Lexical (QSL) from Alib"; more specifically, to the life cycles, that is, the linguistics varieties, which appeared in the answers to the following question: "Women lose blood every month. What do you call that? (Menstruation). To start we will present the taboo in question according to Freud's opinion when he discusses the difference between temporary and permanent taboos. We will also study how this linguistic taboo is studied by scholars like GUÉRIOS (1979) when he shows the significance blood has among all peoples. Beyond this, we will elaborate on the relationship between "purity and danger", which is studied by the Mary Douglas. Based on the theory mentioned, we will follow a path which will establish a contrast among all the maps presented and the conclusions that we can make as general. In this way, we propose a typology of the existing taboos found in the linguistic atlases mentioned. A classification based on GUÉRIOS (1979) will be conducted, followed by an analysis of the lexicon and its varieties. This study intends in the main to display the phenomena of the linguistic taboos, as is recognizable from data recorded in linguistic atlases. The embodied cultures and world views of the different regions of Brazil could lead to deeper study.
\end{abstract}

Keywords: Terminology - Dialectology - Linguistic taboo - Word taboo - linguistic atlas - linguistic variety.

\footnotetext{
Professora da Universidade Estadual de Santa Cruz (UESC/DLA). Email: lauralmeida@bol.com.bre
} 
Resumo: 0 presente trabalho tem por objetivo abordar os tabus linguísticos presentes nos atlas Atlas Prévio dos Falares Baianos (APFB), Atlas Linguístico de Sergipe I (ALSE I), Atlas Linguístico da Paraíba (Alpa). Selecionamos os temas referentes ao item IIHomem do Questionário Semântico-Lexical (QSL) do Alib, mais especificamente aos ciclos da vida, ou seja, variantes linguísticas que ocorreram em resposta à seguinte questão: "as mulheres perdem sangue todos os meses. Como se chama isso? (menstruação). Inicialmente, apresentaremos o tabu em questão conforme a visão de Freud quando ele discute entre tabus temporários e permanentes. Estudaremos como esse tabu Linguístico é visto por teóricos como GUÉRIOS (1979) quando este ressalta 0 significado que o sangue tem em todos os povos. Além disso, traçaremos um paralelo entre "pureza e perigo" que é abordado pela antropóloga Mary Douglas. Sob a luz dos teóricos mencionados, buscaremos traçar um percurso que permita estabelecer um confronto de todos os mapas apresentados e as conclusões que podemos tirar de caráter geral. Dessa forma, visamos propor uma tipologia dos tabus existentes nos atlas linguísticos mencionados. Elaboramos uma classificação com base em GUÉRIOS (1979), seguida de uma análise das lexias e suas variantes. Com este estudo pretendemos traçar um mapeamento da ocorrência deste fenômeno Linguístico nos atlas linguísticos mencionados, mostrando a cultura e a visão de mundo próprias dessas localidades. Busca também contribuir para um estudo mais aprofundado do material apresentado nos atlas linguísticos.

Palavras-chave: Terminologia - Dialetologia - Tabu Linguístico - Palavra tabu - Atlas linguístico - Variante linguística. 
Almeida, Laura de - Aspectos semântico-lexicais dos tabus linguísticos em atlas linguísticos estaduais

\section{Introdução}

Tomando por base uma perspectiva geolinguística, dialetológica, suscitar a necessidade e a importância de analisarmos as variantes linguísticas. 0 corpus é constituído das ocorrências das respostas dadas pelos entrevistados nos seguintes atlas linguísticos: Atlas Prévio dos Falares Baianos (APFB), Atlas Linguístico de Sergipe I (ALSE I), Atlas Linguístico da Paraíba (Alpa), e que demonstrem esses tabus. Por meio desse trabalho, pretendemos contribuir com uma pequena parcela para a análise deste rico material que é o atlas Linguístico. Trabalhando com os tabus linguísticos, poderemos desmistificar a linguagem no sentido de que, devido ao tabu, o falante é levado a produzir mais variações na escolha de suas respostas.

$\mathrm{Na}$ fase preliminar da pesquisa o problema era identificar quais os tabus linguísticos existentes no atlas linguísticos propostos. Era também investigar se havia alguma relação entre o tabu Linguístico e as variantes linguísticas utilizadas para substituir esta lexia. Enfim, era necessário saber as causas e os processos adotados para que determinado tabu Linguístico não fosse proferido por determinada comunidade linguística.

A escolha do referido tema recai na constatação da carência de estudos acerca da linguagem e de seus usos, suas variantes linguísticas, principalmente os referentes ao tabu linguístico. Em nossas leituras e pesquisas bibliográficas encontramos poucas referências desse tema no estudo da língua portuguesa. Contudo, é necessário um direcionamento diversificado dos estudos da linguagem no sentido de que seja aproveitado o material disponível pertencente a estudos já estudados sobre as variações dialetais como, por exemplo, o corpus dos atlas linguísticos estaduais. Sem menosprezar a riqueza que nos proporcionada por meio dos atlas linguísticos existentes no Brasil, observamos porém, que muitos podem proporcionar estudos futuros sobre a linguagem e suas variações dialetais. 
Almeida, Laura de - Aspectos semântico-lexicais dos tabus linguísticos em atlas linguísticos estaduais

0 presente trabalho será norteado pela seguinte hipótese inicial: quanto à variabilidade / diversidade linguística podemos, baseando-nos nos tabus linguísticos, fazermos induções de índole histórica a respeito do caráter "conservador" ou "inovador" dum dialeto. Se os tabus linguísticos contribuem para esta mudança linguística, então podemos afirmar que os tabus linguísticos são fenômenos linguísticos de inovação ou de conservação?

\section{Fundamentação teórica}

Primeiramente, reportar-nos-emos à Antropologia, pois a questão do tabu aparece de forma contundente. Douglas (1966: 148) classificou cuidadosamente os contextos nos quais a sujeira corporal é considerada poderosa. Segundo a autora, ela pode ser usada ritualmente para o bem nas mãos daqueles investidos com poder de benção. 0 sangue, na religião hebraica, era visto como fonte da vida, e não deveria ser tocado, exceto em condições sagradas de sacrifício. Para Douglas (1966: 149) a experiência social e cultural é a chave que explica a irregularidade com que diferentes aspectos do corpo são tratados nos rituais do mundo. Em alguns, a poluição menstrual é temida como um perigo letal; em outros isso não ocorre. FREUD (1950) também compartilha da mesma visão de Douglas referente aos tabus, quando ele faz a distinção entre tabus permanentes e temporários. Sendo que o primeiro refere-se aos ligados aos padres e chefes, assim como às pessoas mortas e qualquer coisa pertencente a elas. Enquanto que os tabus temporários pode ser ligados a certos particulares, tais como a menstruação e o parto, aos guerreiros antes e depois de uma expedição, ou em atividades especiais tais como a pesca e a caça.

Dentre os estudos realizados sobre os tabus linguísticos, que são poucos, vamos nos deter em GuérIos (1979). Em suas pesquisas sobre os tabus 
Almeida, Laura de - Aspectos semântico-lexicais dos tabus linguísticos em atlas linguísticos estaduais

linguísticos, o autor apresenta uma definição para o termo, assim como uma classificação dos mesmos. Uma coisa que podemos observar em seu estudo sobre este tema é a carência de exemplos de tabus linguísticos presentes na língua portuguesa. 0 autor cita exemplos de diversos lugares da Polinésia e outros, porém são muito escassos os exemplos referentes ao Brasil.

Ao definir o tabu Linguístico, Guérios estabelece a existência de dois tipos: próprio e impróprio. 0 primeiro refere-se à proibição de dizer certo nome ou certa palavra, aos quais se atribui poder sobrenatural, e cuja infração causa infelicidade ou desgraça, é mágico-religioso ou de crença. Por sua vez, o segundo tipo refere-se à proibição de dizer qualquer expressão imoral ou grosseira, é, portanto, moral ou de sentimento. Neste trabalho nos deteremos no tabu Linguístico próprio.

Os tabus linguísticos podem propiciar uma maior produtividade de variantes linguísticas no português do Brasil? Existe o lado duvidoso quanto aos benefícios trazidos pelo emprego de tabus linguísticos pelo falante, pois o que pode ocorrer é uma grande quantidade de variantes expressando esses tabus e a possibilidade do esquecimento da palavra que expressa esse tabu.

A área semântica escolhida foi "ciclo da vida". Tomaremos por base 0 Questionário Semânitco-Lexical (QSL) que consta dos Questionários 2001 do Projeto Atlas Linguístico do Brasil (ALiB). No presente trabalho, iremos analisar a seguinte pergunta do QSL: "as mulheres perdem sangue todos os meses. Como se chama isso?"

Centraremos nossa análise na resposta sugerida pelo QSL, ou seja, "menstruação".

Consultando as respostas dadas pelos informantes assim como as notas apresentadas pelo pesquisador que teve que repetir a pergunta a uma certa resistência do informante em dizer "menstruação", constatou-se que essa lexia era um tabu para aquela comunidade entrevistada. GUÉRIOS (1979: 77) não faz referência direta à lexia simples "menstruação" nem tampouco às suas variantes linguísticas. Porém, quando o autor reporta-se aos "tabus em 
Almeida, Laura de - Aspectos semântico-lexicais dos tabus linguísticos em atlas linguísticos estaduais

nomes de membros do corpo" no capítulo 19, ele discute a questão do sangue para os diferentes povos e seu significado:

O sangue, em todos os povos, sempre representou papel importante foi considerado a sede da vida, da alma, ou confundido com a própria vida, atribuindo-se-Ihe força mágica ou sobrenatural, e, por conseqüência, sujeito a tabuagem - sangue da vítima sacrificial, sangue de vítima de homicídio, sangue de animal consagrado ou não (GUÉRIOS 1979: 124).

\section{Desenvolvimento}

\subsection{Análise qualitativa das variantes linguísticas encontradas}

Ressaltamos aqui que o dicionário é considerado fonte fidedigna para considerar se determinada palavra, termo ou expressão faz parte da língua portuguesa. Contudo, analisando o corpus selecionado, verificamos a existência de outras variantes linguísticas que, apesar de não estarem dicionarizadas são formas comprovadas por meio da pesquisadora. A análise mais detalhada dessas outras variantes linguísticas será realizada posteriormente. Consultamos dicionários da língua portuguesa a fim de verificarmos quais variantes linguísticas já estavam dicionarizadas. Segundo 0 Aurélio (FERREIRA 1999), existem variações já dicionarizadas para menstruação: "regra, "boi", "chico", "incômodo", "lua", dentre outras que serão mencionadas posteriormente.

Uma prova que o tabu Linguístico "menstruação", ao mesmo tempo em que denota um certo teor de "conservação" do falante, proporciona também momentos de inovação linguística, pôde ser observado nas variantes 
Almeida, Laura de - Aspectos semântico-lexicais dos tabus linguísticos em atlas linguísticos estaduais

linguísticas que não estão dicionarizadas e que apareceram nos atlas linguísticos analisados:

APFB: "flor vermelha", "matou o pinto", "pote quebrado", "quebrou o pote"; ALSE I: "estar movida", "estar ofendida", "estar de férias", "meus tempo", "estar sem poder";

Alpa: "tá de bode", "tá de vaca", "tá choca".

\subsection{Classificação dos tabus linguísticos}

De acordo com GuérIOs existem meios de substituição dos vocábulos tabus pois, segundo ele,

Se é vedado pronunciar uma palavra, se esta é tabu, então qual é o recurso ou processo de que se lança mão para exteriorizar a idéia expressa por ela, uma vez que se faz mister exprimí-la? (GuérIOs 1979: $11)$.

0 autor ressalta que o recurso empregado são meios indiretos e meios diretos dissimulados, i.e., substitutos que velem de qualquer modo o ser sagrado-proibido. Para realizarmos uma análise qualitativa do corpus baseamo-nos nos estudos de GuéRIos (1979: 12).

\subsubsection{0 vocábulo tabu é substituído por um hipocorístico ou por uma antífrase:}

É uma expressão de carinho ou de louvor que pretende transformar 0 inimigo em amigo, ou neutralizar as forças malignas, como observamos nos exemplos do Atlas Linguísticos: 
Almeida, Laura de - Aspectos semântico-lexicais dos tabus linguísticos em atlas linguísticos estaduais

- Flor vermelha (APFB);

- ironia: estar de boi (ALSE), tá de boi (Alpa), tem que berrar todo mês (ALSE), matou o pinto (APFB), quebrou o pote (APFB), pote quebrado (APFB)

\subsubsection{0 vocábulo tabu é substituído por um disfemismo:}

Guérios descreve disfemismo como uma expressão agravante, como observamos nos exemplos:

- estar doente (ALSE), doente (Alpa), estar assistida (ALSE), estar sem poder (ALSE)

\subsubsection{0 vocábulo tabu apresenta-se no diminutivo:}

- Chico (APFB), Alpa

Segundo o Aurélio (FerReIRA 1979: 459):

"chico" [Hipocorístico de Francisco] S.m. (...) 2. Bras. Pop. V. menstruação (1) (...)."

\subsubsection{O vocábulo tabu é substituído por um sinônimo simples ou locucional:}

- incômodo: incomodada (Alpa), estar incomodada (ALSE), incomodada (ALSE)

- regra:

- estar de regra, regra, regular (ALSE)

- as regras (Alpa),

- regula (APFB) 
Almeida, Laura de - Aspectos semântico-lexicais dos tabus linguísticos em atlas linguísticos estaduais

Consultamos o dicionário a fim de verificarmos a existência de sinônimos da lexia simples "menstruação" já dicionarizados. Dessa forma, confirmamos as variantes constantes no Aurélio (FERREIRA 1999) e que coincidem com as variantes dos atlas estudados, ou seja, "regras, boi, chico, lua, paquete, incômodo".

[De menstruar+- ção] S. f. Fisiol. Gim. 1. Perda fisiológica de sangue de origem uterina, de caráter cíclico, e que, habitualmente a cada período de cerca de quatro semanas (...).

[Sin.: catamênio, menorréia, menarquia, mênstruo, regras e (pop.) boi, chico ${ }^{1}$, conjunção, costume ${ }^{1}$, embaraço, escorrência, incômodo, lua, mês, paquete, período, pingadeira, purgação do mês, sangue, veículo, visita, volta-da-lua] 2. Período menstrual (q.v.) (FerRelRA 1999: 1317).

\subsubsection{0 vocábulo tabu é substituído por uma expressão genérica com ou sem restrição:}

- os tempos (Alpa),

- meus tempos (ALSE)

A seguir, apresentamos um quadro-resumo da classificação apresentada acima: 
Almeida, Laura de - Aspectos semântico-lexicais dos tabus linguísticos em atlas linguísticos estaduais

\begin{tabular}{|c|c|c|c|c|}
\hline Antífrase & Disfemismo & Diminutivo & Sinônimo & $\begin{array}{l}\text { Expressão } \\
\text { genérica com } \\
\text { ou sem } \\
\text { restrição }\end{array}$ \\
\hline $\begin{array}{l}\text { - } \\
\text { vermelha } \\
\text { (APFB); } \\
\text { - ironia: estar } \\
\text { de boi (ALSE } \\
\text { l), tá de boi } \\
\text { (Alpa), tem } \\
\text { que berrar } \\
\text { todo mês } \\
\text { (ALSE I), } \\
\text { matou o pinto } \\
\text { (APFB), } \\
\text { quebrou o } \\
\text { pote (APFB), } \\
\text { pote } \\
\text { quebrado } \\
\text { (APFB) }\end{array}$ & $\begin{array}{ll}\text { - estar doente } \\
\text { (ALSE I), } \\
\text { doente } \\
\text { (Alpa), estar } \\
\text { assistida } \\
\text { (ALSE I), estar } \\
\text { sem poder } \\
\text { (ALSE I) }\end{array}$ & 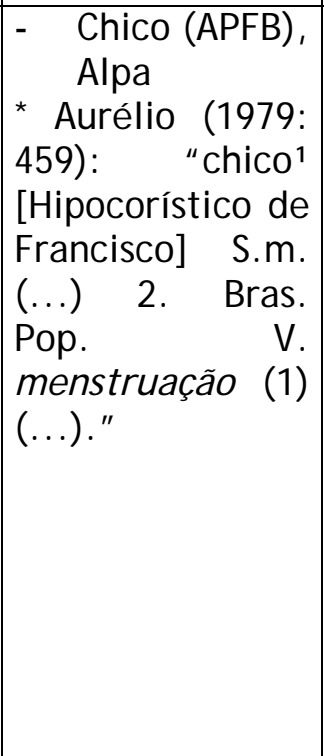 & $\begin{array}{l}\text { - incômodo: } \\
\text { incomodada } \\
\text { (Alpa), estar } \\
\text { incomodada } \\
\text { (ALSE I), } \\
\text { incomodada } \\
\text { (ALSE I) } \\
\text { regra: - estar } \\
\text { de regra, } \\
\text { regra, regular } \\
\text { (ALSE I); as } \\
\text { regras (Alpa), } \\
\text { regula (APFB) }\end{array}$ & $\begin{array}{l}\text { - os tempos } \\
\text { (Alpa), } \\
\text {-meus tempos } \\
\text { (ALSE I) }\end{array}$ \\
\hline
\end{tabular}

Com 0 intuito de nos certificarmos se as variantes linguísticas encontradas nos atlas linguísticos pesquisados já faziam parte da língua portuguesa, consultamos o dicionário Aurélio a fim de verificarmos a existência de sinônimos da lexia simples "menstruação" já dicionarizados. Dessa forma, confirmamos que:

[Sin.: catamênio, menorréia, menarquia, mênstruo, regras e (pop.) boi, chico ${ }^{1}$, conjunção, costume ${ }^{1}$, embaraço, escorrência, incômodo, lua, mês, paquete, período, pingadeira, purgação do mês, sangue, veículo, visita, volta-da-lua] 2. Período menstrual (q.v.) (FerReIRA, 1999: 1317). 
Almeida, Laura de - Aspectos semântico-lexicais dos tabus linguísticos em atlas linguísticos estaduais

\subsection{Análise quantitativa}

Realizamos a coleta do corpus seguindo algumas etapas: leitura criteriosa das cartas linguísticas, organização de tabelas que demonstrassem a ocorrência tanto do tabu Linguístico quanto das variantes relacionadas à mesma lexia que correspondia ao tabu.

Em seguida, elaboramos tabelas que mostrassem, por meio de um levantamento estatístico, os tabus que tivessem o maior número de variantes linguísticas. Dessa forma, suprimimos as variantes que tivessem uma frequência pequena. Com vistas a um tratamento interpretativo, observou-se a etimologia e a origem de algumas palavras em dicionários da língua portuguesa. Inicialmente, apresentamos uma tabela que contém a distribuição da ocorrência, bem como outras informações relativas a algumas variáveis e sua distribuição, e a análise da mesma. A seguir, apresentamos a carta lexical que mostra a distribuição das ocorrências nos atlas em questão.

Inicialmente, apresentamos uma tabela que contém a distribuição da ocorrência, bem como outras informações relativas a algumas variáveis e sua distribuição, e a análise da mesma. A seguir, apresentamos a carta lexical que mostra a distribuição das ocorrências nos atlas em questão. 
Almeida, Laura de - Aspectos semântico-lexicais dos tabus linguísticos em atlas linguísticos estaduais

\section{Menstruação - Alpa}

\begin{tabular}{|l|c|c|}
\hline Variante linguística & Ocorrências & Frequência \\
\hline boi & 14 & $23,33 \%$ \\
\hline doente & 10 & $16,67 \%$ \\
\hline tá de boi & 9 & $15,00 \%$ \\
\hline os tempos & 6 & $10,00 \%$ \\
\hline chico & 5 & $8,33 \%$ \\
\hline tá de bode & 5 & $8,33 \%$ \\
\hline as regras & 4 & $6,67 \%$ \\
\hline menstruada & 3 & $5,00 \%$ \\
\hline incomodada & 2 & $3,33 \%$ \\
\hline tá de vaca & 1 & $1,67 \%$ \\
\hline tá choca & 1 & $1,67 \%$ \\
\hline Total de Variantes & $\mathbf{6 0}$ & $\mathbf{1 0 0 , 0 0 \%}$ \\
\hline & & \\
\hline
\end{tabular}

\section{Menstruação - ALSE I}

\begin{tabular}{|l|c|c|}
\hline Variante linguística & Ocorrências & Frequência \\
\hline estar doente & 5 & $20,83 \%$ \\
\hline estar assistida & 4 & $16,67 \%$ \\
\hline estar de boi & 3 & $12,50 \%$ \\
\hline estar incomodada & 2 & $8,33 \%$ \\
\hline estar menstruada & 2 & $8,33 \%$ \\
\hline estar de regra & 2 & $8,33 \%$ \\
\hline estar movida & 1 & $4,17 \%$ \\
\hline estar ofendida & 1 & $4,17 \%$ \\
\hline estar de férias & 1 & $4,17 \%$ \\
\hline regula & 1 & $4,17 \%$ \\
\hline meus tempo & 1 & $4,17 \%$ \\
\hline estar sem poder & 1 & $4,17 \%$ \\
\hline Total de variantes & $\mathbf{2 4}$ & $\mathbf{1 0 0} \%$ \\
\hline
\end{tabular}


Almeida, Laura de - Aspectos semântico-lexicais dos tabus linguísticos em atlas linguísticos estaduais

\section{Menstruação - APFB}

\begin{tabular}{|l|c|c|}
\hline Variante linguística & Ocorrências & Frequência \\
\hline boi & 37 & $69,81 \%$ \\
\hline lua & 6 & $11,32 \%$ \\
\hline paketi & 3 & $5,66 \%$ \\
\hline boiada & 1 & $1,89 \%$ \\
\hline flor vermelha & 1 & $1,89 \%$ \\
\hline matou o pinto (la menstruação) & 1 & $1,89 \%$ \\
\hline pote quebrado & 1 & $1,89 \%$ \\
\hline quebrou o pote & 1 & $1,89 \%$ \\
\hline regula & 1 & $1,89 \%$ \\
\hline chico & 1 & $1,89 \%$ \\
\hline Total de variantes & $\mathbf{5 3}$ & $\mathbf{1 0 0} \%$ \\
\hline
\end{tabular}

\subsubsection{Análise comparativa das tabelas}

A lexia de maior frequência é a mesma em dois dos três atlas pesquisados, ou seja, "boi", para o Alpa com $23,33 \%$, e o APFB com $69,81 \%$ Já no ALSE I encontramos a expressão "estar de boi" com 12,5\% de frequência. Como pudemos observar a alusão ao "boi" aparece nos três atlas pesquisados. A figura do boi está presente no folclore baiano como podemos observar, quando VIANNA (1981: 33) relata nos folguedos folclóricos o bumbameu-boi e no folclore infantil o acalanto que segundo a autora (idem) estão em franco desaparecimento nas zonas urbanas, quiçá nas rurais. Ela comenta que o "Boi, boi, boi / Boi da cara preta, por ter sido aproveitado numa canção gravada em disco, ainda resiste, incluindo uma variante na letra (recolhida no Recôncavo): 
Almeida, Laura de - Aspectos semântico-lexicais dos tabus linguísticos em atlas linguísticos estaduais

Boi, boi, boi

Boi da cara branca.

Pegue

esse menino

Que tem medo de carranca.

Ao falar da linguagem popular baiana, VIANNA (1981: 12) ressalta que para doenças o baiano comum tem o seu ementário, sendo que se refere a "dor-de-madre", "dor-do-mês" ou "dor-de-boi" para cólica menstrual.

\section{Considerações finais}

Tivemos por objetivo descrever os aspectos semântico-lexicais no que tange à língua portuguesa, com enfoque na identificação dos tabus linguísticos manifestados nos Atlas Prévio dos Falares Baianos (APFB), Atlas Linguístico de Sergipe I (ALSE I), e do Atlas Linguístico da Paraíba (Alpa). Oferecemos assim aos interessados uma amostragem de estudo possível sobre as variantes linguísticas do Brasil e uma reflexão sobre as mesmas, ampliando o universo de estudo existente. Buscamos também contribuir para o entendimento dos mecanismos de controle social existente na língua portuguesa que se impõe ao falante por meio dos tabus.

Podemos observar que a lexia "boi" teve o maior número de ocorrências no corpus, equivalente a $69,81 \%$ de todas as ocorrências. Observamos que algumas palavras elencadas por alguns dicionários como sinônimos de menstruação apareceram também nesse corpus. Observamos que as formas: "regras", "boi", "chico", "incômodo", "lua", "paquete" estão dicionarizadas. Relatamos a existência de neologismos, isto é, criações apresentadas pelo informante pesquisado, ou seja, "flor vermelha", "matou 0 pinto", "pote quebrado", "quebrou o pote", "estar movida", "estar ofendida", "estar de férias", "meus tempo", "estar sem poder", "tá de bode", "tá de vaca", "tá choca". 
Almeida, Laura de - Aspectos semântico-lexicais dos tabus linguísticos em atlas linguísticos estaduais

No início deste trabalho, levantamos a hipótese que se os tabus linguísticos contribuem para a mudança linguística, então poderíamos afirmar que os tabus linguísticos seriam fenômenos linguísticos de inovação ou de conservação. Verificamos, no caso dos atlas linguísticos analisados, que o tabu Linguístico apresenta indícios tanto de inovação quanto de conservação linguística, pois existem variantes linguísticas que se utilizam os meios de substituição do tabu Linguístico apresentados por Guérios, como no caso dos hipocorísticos: Flor vermelha (APFB); ironia: estar de boi (ALSE I), tá de boi (Alpa), tem que berrar todo mês (ALSE I), matou o pinto (APFB), quebrou 0 pote (APFB), pote quebrado (APFB). Também no caso nos disfemismos: estar doente (ALSE I), doente (Alpa), estar assistida (ALSE I), estar sem poder (ALSE 1). Ou quando o vocábulo tabu apresenta-se no diminutivo: Chico (APFB), Alpa. Ou ainda, quando o vocábulo tabu é deformado foneticamente: tá de boi / de vaca/ de bode/ choca. Existe também a substituição do vocábulo tabu por um sinônimo simples ou locucional: incômodo: incomodada (Alpa), estar incomodada (ALSE I), incomodada (ALSE I), regra: estar de regra, regra, regular (ALSE I); as regras (Alpa), regula (APFB). Finalizando, citamos o caso em que o vocábulo tabu é substituído por uma expressão genérica com ou sem restrição: os tempos (Alpa), meus tempos (ALSE I). Em relação aos elementos de conservação linguística, confirmamos a hipótese que devido ao tabu Linguístico "menstruação", os informantes optam pelo uso das variantes.

Buscamos, por meio deste trabalho, contribuir para os estudos dos aspectos semântico-lexicais dos atlas linguísticos e esperamos que estudos posteriores venham a ampliar o campo de estudos geolinguísticos e dialetológicos. Ressaltamos, que embora existam peculiaridades na constituição dos diferentes atlas linguísticos publicados no Brasil, é possível que façamos estudos acerca de semelhanças e diferenças sobre os mesmos. 


\section{Referências bibliográficas}

Aragão, M. do S. S. de; Menezes, C. B. de Atlas Linguístico da Paraíba.: v.1; cartas léxicas e fonéticas. Brasília: UFBA/ CNPq, 1985.

DouglaS, M. Pureza e perigo, São Paulo: Perspectiva, 1966.

FerReIRA, A . B. H. Novo dicionário Aurélio Século XXI: o dicionário da língua portuguesa. 3. ed. ver. e ampl. Rio de J aneiro: Nova Fronteira, 1999.

FERREIRA, C. da S. et al. Atlas Linguístico de Sergipe. Salvador: UFBa/ FUDESC, 1987.

Freud, S. Totem and Taboo. Great Britain: Routledge \& Kegan Paul, 1950.

GuérIOS, R. F. M. Tabus linguísticos. São Paulo: Nacional, 1979.

RossI, N. Atlas Prévio dos falares baianos. Rio de J aneiro: INL; MEC, 1963.

VIANNA, H. Folclore brasileiro - Bahia. Rio de Janeiro: Portinho Cavalcanti, 1981. 
Almeida, Laura de - Aspectos semântico-lexicais dos tabus linguísticos em atlas linguísticos estaduais

\section{APÊNDICE}

Quadro-resumo dos atlas analisados

\begin{tabular}{|c|c|c|c|}
\hline & APFB & $\mathrm{ALPa}$ & ALSE I \\
\hline Publicação & 1963 & 1984 & 1987 \\
\hline Localidades & 50 & 100 & 15 \\
\hline Pontos & 599 & 25 & 15 \\
\hline $\begin{array}{l}\text { Questionário } \\
\text { (no perguntas) }\end{array}$ & $E Q=182$ & $\begin{array}{l}289 \text { (geral) } \\
588 \text { (específica) }\end{array}$ & 700 \\
\hline Informantes & 100 & 107 & 30 \\
\hline № e tipo de cartas & $\begin{array}{l}154 \quad \text { cartas } \\
\text { linguísticas } \\
44 \text { cartas-resumo }\end{array}$ & $\begin{array}{l}149 \text { cartas } \\
\text { léxicas e fonéticas }\end{array}$ & $\begin{array}{l}182 \text { Linguísticas e não } \\
\text { linguísticas }\end{array}$ \\
\hline Autores & Rossi, Nelson et al. & Aragão, Mạ do S. S. de & Ferreira, C. da S. et al. \\
\hline Faixa etária & 25 a 60 anos & 30 a 75 anos & 30 a 60 anos \\
\hline Metodologia & $\begin{array}{l}\text { Interrogação } \\
\text { indireta/ } \\
\text { transcrição } \\
\text { imediata }\end{array}$ & entrevistas & Baseada no APFB \\
\hline Áreas semânticas & Terra e homem & $\begin{array}{l}\text { Terra, homem, família } \\
\text { e utensílios domésticos, } \\
\text { aves e animais, } \\
\text { plantação e atividades } \\
\text { sociais }\end{array}$ & Terra e homem \\
\hline $\begin{array}{lr}\text { Tempo } & \text { de } \\
\text { confecção do Atlas }\end{array}$ & $\begin{array}{l}1960-1963 \\
3 \text { anos }\end{array}$ & $\begin{array}{l}1979-1984 \\
5 \text { anos }\end{array}$ & $\begin{array}{l}1973-1987 \\
14 \text { anos }\end{array}$ \\
\hline
\end{tabular}

